\title{
Prevalence of Mycobacterium tuberculosis (Rifampicin- Resistant MTB) and Associated Risk Actors Among Pulmonary Presumptive TB Patients in Eastern Amhara, Ethiopia: 2015-2019
}

Araya Gebreyesus Wasihun · Genet Gebrehiwet Hailu •

Tsehaye Asmelash Dejene

Received: September 3, 2020 / Accepted: October 24, 2020 / Published online: May 5, 2021

(c) The Author(s) 2021

\section{ABSTRACT}

Introduction: Tuberculosis (TB) is a major health problem, mainly in resource-limited settings. The aim of this study was to determine the prevalence of TB and rifampicin-resistant Mycobacterium tuberculosis (RR-MTB) among presumptive tuberculosis patients using Xpert MTB/RIF assay in Eastern Amhara, Ethiopia.

Methods: A retrospective cross-sectional study was conducted among presumptive TB patients from three governmental hospitals in Amhara Regional State. Records of sputum sample results using Xpert MTB/RIF assay from January 2015 to December 2019 were investigated from registration books and analyzed using SPSS v.21. Results: Of the total of $26,656(24,116$ adults and 2540 children) TB presumptive patients included in the study, more than half, 14,624 $(54.9 \%)$, were males and the median age was 36.87 (interquartile: $25.46-50.85$ years). The majority of participants were new cases, 20,273 (76.1\%), and with unknown HIV status, 18,981

A. G. Wasihun ( $₫)$ · G. G. Hailu · T. A. Dejene Department of Medical Microbiology and Immunology, School of Medicine, Mekelle University, Mekelle, Ethiopia

e-mail: araya13e25@gmail.com

T. A. Dejene

Department of Medical Microbiology and Immunology, School of Medicine, Aksum University, Aksum, Ethiopia
(71.2\%), respectively. MTB prevalence was $11 \%$ (95\% CI: 9.34-12.08\%) in all age groups, and 7.6\% (95\% CI 6.52-9.04\%) among children. Of the MTB confirmed cases, prevalence of RR-MTB was $245(8.3 \%)$ in adults and $14(7.2 \%)$ in children. MTB infection was higher in the age groups of $18-35$ years [adjusted odds ratio $(\mathrm{AOR})=2.17 ; 95 \% \mathrm{CI}: 1.86-2.54, p<0.001]$, $36-53$ years $(\mathrm{AOR}=1.31 ; 95 \%$ CI $1.11-1.54$, $p<0.001)$, those who were relapse cases $(\mathrm{AOR}=1.97 ; 95 \%$ CI 1.69-2.27, $\mathrm{p}<0.0010)$, and failure cases $(\mathrm{AOR}=4.67 ; 95 \% \quad \mathrm{CI}$ $3.36-6.50, p<0.001)$. However, the age groups of $54-71$ years $(\mathrm{AOR}=0.79 ; 95 \%$ CI $0.65-0.95$, $p=0.01)$ and over 71 years $(\mathrm{AOR}=0.48 ; 95 \% \mathrm{CI}$ $0.35-0.68, \mathrm{p}<0.001)$ were associated with lower MTB infection. Resistance to rifampicin was higher in the relapsed $(\mathrm{AOR}=2.10 ; 95 \% \mathrm{CI}$ $1.40-3.03, p<0.001)$ and failure cases $(\mathrm{AOR}=$ 3.50; 95\% CI 1.9-6.61, $p<001)$.

Conclusion: Prevalence of MTB and RR-MTB low. TB infection was higher in adult age groups and those who had previous TB treatment history. Similarly, resistance to rifampicin was higher among the relapsed and failure patients. Appropriate measurements in monitoring of $\mathrm{TB}$ treatment could reduce TB and RR-MTB in the study area.

Keywords: Amhara; Ethiopia; Presumptive TB; RR-MTB; Xpert MTB/RIF assay 


\section{Key Summary Points}

Tuberculosis (TB) and rifampicin-resistant (RR) MTB is a major health issue, mainly in resource-limited settings like Ethiopia.

Since the introduction of Xpert MTB/RIF, assay data on TB and RR-MTB are limited in the nation.

The detection rate of TB and RR-MTB increases with the Xpert method.

MTB prevalence was 2941 (11\%) in all age groups, and 194 (7.6\%) among children.

TB infection was higher in adult age groups and those who had previous $\mathrm{TB}$ treatment history.

RR-MTB was higher among relapsed and failure patients.

\section{DIGITAL FEATURES}

This article is published with digital features, including a summary slide, to facilitate understanding of the article. To view digital features for this article go to https://doi.org/10.6084/ m9.figshare.13130075.

\section{INTRODUCTION}

Tuberculosis (TB) is one of the top ten causes of mortality and the first killer among infectious diseases worldwide. Multidrug-resistant Mycobacterium tuberculosis (MDR-MTB), defined as resistant to at least isoniazid and rifampicin, is a major global health problem. According to the World Health Organization (WHO), in 2019, an estimated 10.0 million people globally were infected with $\mathrm{TB}$ and about 1.2 million $\mathrm{TB}$ deaths were reported among human immunodeficiency virus (HIV)-negative people in 2018. Similarly, about half a million new cases of rifampicin-resistant (RR) TB (of which $78 \%$ had MDR TB) were reported in 2018 [1]. The high burden of TB and MDR-TB in low-income countries is associated with a delay in early diagnosis and appropriate treatment initiation, and a high prevalence of HIV [2].

Rapid detection, earlier treatment initiation, continuous surveillance, and regular monitoring of drug-resistant TB are essential for disease management and control program [3]. To alleviate the problem associated with early diagnosis of TB in low-income countries, the WHO endorsed Xpert MTB/RIF (Cepheid, Sunnyvale, CA, USA) in December 2010, the first automated molecular system which detects both MTB and RR concurrently [4]. RR-MTB is a proxy marker for MDR-TB in more than $90 \%$ of the cases [5]. Firstly, the method was recommended for patients with TB/HIV co-infection, suspected MDR-TB, and paediatrics [6]. However, 3 years after its implementation, it was indicated for all TB presumptive patients [7]. Ethiopia introduced Xpert MTB/RIF assay for the diagnosis of TB and RR-MTB in 2014 [8].

Ethiopia is among the 30 high TB, TB/HIV, and MDR-TB burdened countries with a rank of 15th among high MDR-TB countries with more than 5800 estimated MDR-TB cases each year [9]. A systematic review conducted in Ethiopia reported $2.18 \%$ and $21.07 \%$ prevalence of MRDTB among new and pre-treatment cases, respectively [10]. Studies so far carried out in Ethiopia have used the conventional culture and sensitivity methods, not the automated Xpert MTB/RIF assay. Few Xpert MTB/RIF assay studies have been conducted in Ethiopia, e.g., in Addis Ababa [11], Amhara Regional State [4], and southern Ethiopia [12], which reported a prevalence of $15.11-23.2 \%$ and $3.4-10.3 \%$ for MTB and RR-MTB, respectively [4, 11, 12].

However, the studies from the Amhara region and southern Ethiopia were carried out in single hospitals, and their sample size was small. The study conducted in Addis Ababa included a larger sample size (12,414 samples) and four health facilities; however, it cannot represent the prevalence at the national level. Hence, the limited information from previous studies calls for more data, with a representative sample in order to forward reasonable findings and recommendations to help policymakers 
and implementers to plan and design proper intervention strategies to control TB.

In Amhara Regional State, there was one cross-sectional study on RR-MTB conducted from September 2014 to March 2015 on 505 presumptive TB patients with a RR-MTB prevalence of $17.1 \%$ [4]. This study cannot represent the RR-MTB status of the whole region. Therefore, having representative data in the region will fill the existing knowledge gap and provide up-to-date information for policymakers and implementers.

\section{METHODS}

\section{Study Setting, Study Design and Study Population}

Amhara Regional State is located in the northwestern part of Ethiopia. According to the 2007 census conducted by the Central Statistical Agency of Ethiopia, the region has a population of $17,221,976$ and an area of $154,708.96 \mathrm{~km}^{2}$. It is bordered by Tigray Region in the north, Afar in the rast, Oromiya in the south, BenishangulGumiz in the southwest, and Sudan in the west. Health services in the region are provided by 5 referral hospitals, 2 general hospitals, 73 primary hospitals, 847 health centers, and 3342 village clinics [13].

A retrospective cross-sectional study design was used to collect data from January 2015 to December 2019 from 2 referral hospitals and 1 general hospital. The hospitals are the Woldiya general hospital, and the Dessie and DebeBrhan comprehensive specialized hospitals located in three zones of the region (North Wollo, South Wollo, and Semen Shewa). Directly observed treatment, short-course TB treatment services are given in all the health facilities. The study population were all pulmonary TB presumptive patients who visited the hospitals between January 2015 and December 2019 (Fig. 1).

Inclusion criteria We included all presumptive pulmonary TB patients with complete records of age, sex, Xpert MTB/RIF results, HIV status, and TB treatment history.

Outcome Variable MTB and RR-MTB among presumptive pulmonary TB patients.

Independent Variables Age, gender, HIV status and TB treatment history.

Data Collection Patient's data such as age, gender, and clinical-related data (Xpert MTB/ RIF results, HIV status, and $\mathrm{TB}$ treatment

Total Xpert MTB/RIF tests done from 2015-2019 ( N=28, 061)

Eligible tests ( $N=26,656)$

- New cases $n=20273$

- Relapse $n=1376$

- Lost to follow up $n=4849$

- Failure $\mathrm{n}=158$
Excluded tests $(\mathrm{N}=1405)$

- No data on age: $n=45$

- No data on gender: $n=39$

- Invalid Xpert result: $n=984$

- Intermediate Xpert result : $n=175$

- No data on HIV: $\mathrm{n}=86$

- No data on TB treatment history: $n=76$

RR-MTB: $n(\%)=245(8.3)$

Fig. 1 Flow chart for inclusion and exclusion criteria 
history) were collected using the data extraction sheet from Xpert MTB/RIF registration books in each health facility.

\section{Laboratory Processing}

A single sputum sample per patient was used for the diagnosis of TB using the Xpert MTB/RIF assay. Samples were collected and processed by the Xpert MTB/ RIF assay using the standard protocol. Briefly, after the sputum was collected, it was mixed in the supplied cartridge with sample reagent buffer in 1:2 (sample:sample reagent buffer) volume ratio. Then, the cartridge was tightly closed, vortexed for $15 \mathrm{~s}$, and allowed to stand at room temperature for $10 \mathrm{~min}$. It was vortexed again after $10 \mathrm{~min}$ and allowed to stand for $5 \mathrm{~min}$. Using the Pasteur pipette provided with the kit, $>2 \mathrm{ml}$ (just above $2 \mathrm{ml}$ mark on the pipette) of the processed sample was put into the cartridge. Finally, the cartridge with the specimen was loaded into the Xpert machine and the results were collected from the Xpert computer after $2 \mathrm{~h}$ [14].

\section{Quality Control and Data Analysis}

After data completeness was checked, the data were entered and analyzed using SPSS v.21. Frequency, mean, range, and standard deviation were computed. Using an Enter modeling method, potential candidates associated with the outcome variables (MTB and RR-MTB) in bivariate analysis at a significance level of 0.25 were identified and exported to multivariable logistic regression analysis. Confidence intervals (CI) of 95\% were reported for each odds ratio (OR). All reported $p$ values were two-tailed, and statistical association was set as significant at a $p$ value $\leq 0.05$.

\section{Ethical Issues}

Ethical clearance was secured from Institutional Review Board (IRB) of Aksum University; College of Health Sciences. Moreover, a letter of cooperation was written to each study hospital and permission to collect the data was obtained from the Amhara Public Health Institute, Dessie branch (Ref: 4/49/2019).

\section{RESULTS}

\section{Socio-demographic, Clinical Characteristics and TB Results}

Of the total 28,061 presumptive TB patients who provided sputum samples for TB diagnosis, 26,656 (95\%) had complete data and were included in this study. More than half, 14,624 $(54.9 \%)$, were males and the median age was 36.87 (interquartile range: 25.46-50.85 years; range 6 months -109 years). The majority of the patients were treatment-naïve, 20,273 (76.1\%), and with unknown HIV status, 18,981 (71.2\%), respectively. According to the results of this study, the prevalence of MTB was 2941 (11\%). Of these, RR-MTB numbered 245 (8.3\%) (Table 1).

\section{Associated Risk Factors of MTB Infections}

Patients whose age group was $18-35$ years $(\mathrm{AOR}=2.17 ; 95 \%$ CI: 1.86-2.54, $p<0.001)$, $36-53$ years $(\mathrm{AOR}=1.31 ;$ 95\% CI $1.11-1.54$, $p<0.001)$ were more infected compared the children age group ( $\leq 17$ years), whereas the age groups of $54-71$ years $(\mathrm{AOR}=0.79 ; 95 \% \mathrm{CI}$ $0.65-0.95, p=0.01)$ and over 71 years $(\mathrm{AOR}=$ 0.48 ; 95\% CI $0.35-0.68, p<0.001$ ) were associated with lower MTB. Similarly, the odds of contracting TB among relapsed and failure cases were 1.97 and 54.67 times, respectively, more compared the new patients. (Table 2).

\section{Associated Risk Factors of RR-MTB}

Of the total 2,941 MTB confirmed patients, 245 $(8.3 \%)$ of them were positive for RR-MTB. Relapsed patients (AOR $=2.10 ; \quad 95 \% \quad$ CI 1.40-3.03, $p<0.001)$ and failure cases $(\mathrm{AOR}=$ 3.5 ; 95\% CI 1.9-6.61, $p<0.001$ ) were more likely to have RR-MTB compared to the new cases (Table 3). 
Table 1 Socio-demographic, clinical characteristics, and MTB results of TB presumptive patients in Eastern Amhara, Ethiopia, 2015-2019 $(n=26,656)$

\begin{tabular}{lc}
\hline Variables & $\boldsymbol{n}(\%)$ \\
\hline Gender & \\
Male & $14,624(54.9)$ \\
Female & $12,032(45.1)$ \\
Age (years) & \\
$\leq 17$ & $2540(9.5)$ \\
18-35 & $10,365(38.9)$ \\
$36-53$ & $7658(28.7)$ \\
$54-71$ & $5012(18.8)$ \\
$\geq 72$ & $1081(4.1)$ \\
HIV status & \\
Positive & $2826(10.6)$ \\
Negative & $4849(18.2)$ \\
Unknown & $18,981(71.2)$ \\
TB treatment history & \\
New case & $20,273(76.1)$ \\
Relapsed & $1376(5.2)$ \\
Lost to follow-up & $4849(18.2)$ \\
Failure & $158(0.6)$ \\
MTB result & \\
Positive & $2941(11)$ \\
Negative & \\
RR-MTB result $n=2941)$ & \\
RR-MTB-positive & \\
RR-MTB-negative & \\
\hline & \\
& \\
&
\end{tabular}

\section{Prevelance of MTB and RR-TB by Years}

Table 4 compares the prevalence of MTB and RR-MTB by study years. Our study revealed that MTB prevalence decreased from $13.9 \%$ in 2015 to $8.8 \%$ in 2017 , then slightly increased to $9.5 \%$ in 2018 and $9.3 \%$ in 2019. Similarly, the prevalence of RR-MTB showed a significant decline from $17.3 \%$ in 2015 to $5.1 \%$ in 2019 (AOR (95\% CI) 1.93 (1.81-2.14, $p<0.001$; data not shown) (Table 4 ).

\section{DISCUSSION}

Having local epidemiological data on MTB and RR-MTB and identification of potential predisposing factors helps to design an appropriate intervention methods to control the disease. In this study, the overall prevalence of MTB and RR-MTB were $11 \%$ and $8.3 \%$, respectively. Our prevalence $11 \%$, was comparable with previous reports from in Addis Ababa, 12.46\% [15], and South Africa, 13\% [16]. This was, however, lower than other studies conducted in Ethiopia, $15.11-60.4 \%[4,11,12,17-21]$, and other similar African countries: Congo, 79.1\% [22], Togo, 57\% [23], Nigeria, 19.1-22.9\% [24, 25], and Uganda, 20.9\% [26]. However, our prevalence was higher than studies carried out in Addis Ababa, 6\% [27], Amhara region, 8\% [28], Oromia region, 3.8\% [29] and Uganda, 5.5\% [30].

The discrepancy might be due to differences in diagnostic modalities, study participants, study period, sample size, geographical, and TB control practices. The high prevalence of TB in other studies [12, 18, 19, 21-23], for example, was because their study participants were MDR suspected patients (relapse, defaulter, lost, and failure), but, in this study, $76.1 \%$ of the participants were TB presumptive patients. Another possible reason for the high $\mathrm{TB}$ recovery in other reports $[20,25]$ was due to their small sample size (small sampling can cause higher prevalence rate).

The higher $\mathrm{TB}$ prevalence in this study compared to the study in Uganda [30] might be due to the fact that the study participants in Uganda were paediatric age groups ( 2 months-12 years) who are less likely to be infected by TB, whereas our participants included all age groups with $90.5 \%$ of them were adults who are more likely to be infected compared to children [1]. The higher prevalence of TB compared with studies conducted in Somalia region [17] and Togo [23] might be because their study period was from 2011 to 2014 where 
Table 2 Prevalence of MTB by gender, age, treatment history, and HIV status among TB presumptive patients in Eastern Amhara, Ethiopia, 2015-2019 $(n=26,656)$

\begin{tabular}{|c|c|c|c|c|c|c|}
\hline Variables & MTB pos. $n(\%)$ & MTB neg. $n(\%)$ & COR $(95 \% \mathrm{CI})$ & $p$ value & $\operatorname{AOR}(95 \% \mathrm{CI})$ & $p$ value \\
\hline \multicolumn{7}{|l|}{ Gender } \\
\hline Male & $1653(11.3)$ & $12,971(88.7)$ & Ref & & & \\
\hline Female & $1288(10.7)$ & $10,744(89.3)$ & $0.94(0.87-1.02)$ & 0.37 & & \\
\hline \multicolumn{7}{|l|}{ Age } \\
\hline$\leq 17$ & $194(7.6)$ & $2346(92.4)$ & Ref & & Ref & \\
\hline $18-35$ & $1621(15.6)$ & $8744(84.4)$ & $2.24(1.92-2.62)$ & $<0.001$ & $2.17(1.86-2.54)$ & $<0.001^{*}$ \\
\hline $36-53$ & $770(10.1)$ & $6888(89.9)$ & $1.35(1.15-1.60)$ & $<0.001$ & $1.31(1.11-1.54)$ & $<0.001^{*}$ \\
\hline $54-71$ & $313(6.2)$ & $4699(93.8)$ & $0.81(0.67-0.97)$ & 0.02 & $0.79(0.65-0.95)$ & $0.01^{*}$ \\
\hline$\geq 72$ & $43(4)$ & $1038(96)$ & $0.50(0.36-0.70)$ & $<0.001$ & $0.48(0.35-0.68$ & $<0.001^{*}$ \\
\hline \multicolumn{7}{|c|}{ HIV status $(n=7675)$} \\
\hline Positive & $357(12.6)$ & $2469(87.4)$ & $1.01(0.88-1.16)$ & 0.93 & & \\
\hline Negative & $609(12.6)$ & $4240(87.4)$ & Ref & & & \\
\hline \multicolumn{7}{|c|}{$\mathrm{TB}$ treatment history } \\
\hline New case & $2093(10.3)$ & $18,180(89.7)$ & Ref & & Ref & \\
\hline Relapse & $258(18.8)$ & $1118(81.2)$ & $2.0(1.74-2.31)$ & $<0.001^{*}$ & $1.97(1.69-2.27)$ & $<0.001^{*}$ \\
\hline Lost & $530(10.9)$ & $4319(89.1)$ & $1.07(0.96-1.18)$ & 0.215 & $1.10(0.95-1.16)$ & 0.34 \\
\hline Failure & $60(38)$ & $98(62)$ & $5.32(3.85-7.36)$ & $<0.001^{*}$ & $4.67(3.36-6.5)$ & $<0.001^{*}$ \\
\hline
\end{tabular}

${ }^{*} p<0.05$ statistically significant

the Xpert assay was recommended for patients with TB/HIV co-infection, presumptive MDR-TB and paediatric TB patients, while this study collected data from 2016 to 2019 where the method was used for all TB suspected patients.

Participants whose age was $18-35$ years $(p<0.001)$ were more likely to be infected by TB compared to children. Although there is no clear-cut value for age among studies, other studies have reported a higher prevalence in different age groups: $16-30$ years [12] and 25-34 years [20], while others have reported no association between age and TB infection $[2,11,19,24]$. The high prevalence of TB among the productive age groups of 18-35 years and $36-53$ years in this study may indicate that $\mathrm{TB}$ is circulating in the community, which needs more attention to combat the problem.
We also report significantly higher MTB among previously treated patients (failure, relapsed) which was in line with the report by Adane and his colleagues [20]. The higher MTB prevalence in the previously treated patients highlight due attention to the DOT program, as this may indicate high TB transmission to new TB cases in the community and, in the case of relapse, the lack of $\mathrm{TB}$ treatment monitoring and control.

RR-MTB (8.3\%) in our study is in line with previous reports from Ethiopia, 9.9-10.3\% [4, 11], and Nigeria, 7.3\% [31]. However, our prevalence is lower than previous similar studies conducted in other parts of Ethiopia: $11-54 \%$ $[18,19,21,27,32]$, Congo, 42.2\% [22], Nigeria, $14.7 \%$ [25], and Togo, 24\% [23]. In contrast, studies from Ethiopia, $1.2-4.7 \%$ 
Table 3 Prevalence of RR-MTB among adult TB patients by sex, age, treatment history and HIV status in Eastern Amhara, Ethiopia, 2015-2019 $(n=2941)$

\begin{tabular}{|c|c|c|c|c|c|c|}
\hline Variables & RR-MTB $n$ (\%) & Not RR-MTB $n(\%)$ & COR $(95 \% \mathrm{CI})$ & $p$ value & $\operatorname{AOR}(95 \% \mathrm{CI})$ & $p$ value \\
\hline \multicolumn{7}{|l|}{ Gender } \\
\hline Male & $138(8.3)$ & $1515(91.7)$ & Ref & & & \\
\hline Female & $107(8.3)$ & $1181(91.7)$ & $0.99(0.76-1.3)$ & 0.97 & & \\
\hline \multicolumn{7}{|l|}{ Age } \\
\hline$\leq 17$ & $14(7.2)$ & $180(92.8)$ & Ref & & & \\
\hline $18-35$ & $152(9.4)$ & $1469(90.6)$ & $1.33(0.75-2.35)$ & 0.32 & & \\
\hline $36-53$ & $56(7.3)$ & $714(92.7)$ & $1.01(0.55-1.85)$ & 0.98 & & \\
\hline $54-71$ & $20(6.4)$ & $293(93.6)$ & $0.88(0.43-1.78)$ & 0.72 & & \\
\hline$\geq 72$ & $3(7)$ & $40(93)$ & $0.96(0.27-3.51)$ & 0.96 & & \\
\hline \multicolumn{7}{|c|}{ HIV status $(n=966)$} \\
\hline Positive & $41(11.5)$ & $316(88.5)$ & $1.07(0.71-1.61)$ & 0.76 & & \\
\hline Negative & $66(10.8)$ & $543(89.2)$ & Ref & & & \\
\hline \multicolumn{7}{|c|}{ TB treatment history } \\
\hline New case & $154(7.4)$ & $1939(92.6)$ & Ref & & Ref & \\
\hline Relapse & $40(15.5)$ & $218(84.5)$ & $2.3(1.59-3.36)$ & $<0.001$ & $2.1(1.4-3.03)$ & $<0.001$ \\
\hline Lost & $37(7)$ & $493(93)$ & $0.95(0.65-1.37)$ & 0.77 & $0.98(0.65-1.40$ & 0.76 \\
\hline Failure & $14(23.3)$ & $46(76.7)$ & $3.8(2.06-7.13)$ & $<0.001$ & $3.5(1.90-6.60)$ & $<0.001$ \\
\hline
\end{tabular}

$[2,12,20,29,33]$, have reported lower RR-MTB prevalence than this study.

Disparities in the results could be due to variations in geographical, methodology (sample size, method of drug resistance diagnosis,

Table 4 Prevelance of MTB and RR- TB by years in Eastern Amhara, Ethiopia, 2015-2019 $(n=26,656)$

\begin{tabular}{lccc}
\hline Year & $\begin{array}{l}\text { Total } \\
\text { patients }\end{array}$ & $\begin{array}{l}\text { MTB } \\
\text { positive } \\
\boldsymbol{n}(\%)\end{array}$ & $\begin{array}{l}\text { RR-MTB } \\
\text { positive } \boldsymbol{n}(\%)\end{array}$ \\
\hline 2015 & 1625 & $225(13.9)$ & $39(17.3)$ \\
2016 & 4321 & $550(12.7)$ & $362(6.6)$ \\
2017 & 4096 & $362(8.8)$ & $26(7.2)$ \\
2018 & 5979 & $566(9.5)$ & $36(6.4)$ \\
2019 & 10,635 & $993(9.3)$ & $51(5.1)$ \\
$2015-2019$ & 26,656 & $2941(11)$ & $245(8.3)$ \\
\hline
\end{tabular}

study participants), study setting, and study period and MDR-TB monitoring and control practice. The high RR-MTB prevalence in Ethiopia $[18,19,21]$ is because their study participants were MDR-TB suspected unlike the presumptive TB patients included in this study. The lower RR-MTB report by Hamusse et al. [29] could be due to the fact that the study was community-based, not a health service-based one. Likewise, the study participants reported from Uganda were paediatric age, who are less prone to TB and MDR compared to adults [30].

In the present study, gender was not associated with RR-MTB; however, others [11, 21] have indicated more RR-MTB among females compared to males. In contrast, other studies have reported more RR-MTB infection among males $[24,31,32]$. The other factor which was a predictor of RR-MTB in this study was previous TB treatment. This is in agreement with previous reports elsewhere [11, 19, 21, 24]. This 
could be related to poor compliance by patients or clinicians, lack of treatment supervision, inappropriate drug regimens, and inadequate or irregular drug supply that make the bacteria mutate and develop drug resistance [34]. This highlights the need for coordinated work among stakeholders to improve the monitoring of treatment to reduce the emergence and circulation of drug-resistant MTB strains in the community.

Our study also tried to investigate the trend of TB and RR-MTB over the study periods. Accordingly, this study revealed that MTB prevalence decreased from $13.9 \%$ in 2015 to $8.8 \%$ in 2017 , then slightly increased to $9.5 \%$ in 2018 and to $9.3 \%$ in 2019. Similarly, the prevalence of RR-MTB showed a significant decline from $17.3 \%$ in 2015 to $5.1 \%$ in 2019 . The increased MTB and RR-MTB in 2015 in our study could be because, during 2015, Xpert in Ethiopia was indicated for patients with TB/HIV co-infection, MDR-TB suspected, and paediatrics. However, later, it was recommended for all $\mathrm{TB}$ presumptive patients and, while the number of patients diagnosed were significantly increased through the years, the number of positive cases decreased.

Our study has limitations. First, as the study was conducted in one region, it cannot represent the prevalence at national level. Second, microbiological confirmation of the Xpert-positive TB and RR-MTB, phenotypic rifampicin resistance, and resistance to other anti-TB drugs was not carried out due to the nature of the study. Third, information on the contact history of MDR-TB and TB, living conditions, and education of study participants was not obtained; therefore, we could not show the associations of MTB and RR-MTB. Hence, the results of this study should be interpreted with due consideration to these limitations.

\section{CONCLUSION}

The overall prevalence of MTB and RR-MTB was $11 \%$ and $8.3 \%$, respectively. Adults and those who were relapsed and or failed were found to be significantly associated with MTB infection. Similarly, relapsed and failure cases were independent predictors of RR-MTB. The strong association of MTB and RR-MTB with relapse and failure highlights the need for coordinated work of the regional government and other stakeholders to improve the monitoring of TB treatment and to minimize the magnitude of any further emergence of drug-resistant TB in the community. Although the prevalence of RRMTB shows a decreasing trend over the study period, it still shows that more work should be carried out to further combat drug-resistant-associated morbidities and mortalities in the study area.

\section{ACKNOWLEDGEMENTS}

We would like to thank all the hospital directors and laboratory staff of the study hospitals for their co-operation in allowing the researchers to access the records and extract the data.

Funding. No funding or sponsorship was received for this study or publication of this article.

Authorship. All named authors meet the International Committee of Medical Journal Editors (ICMJE) criteria for authorship for this article, take responsibility for the integrity of the work as a whole, and have given their approval for this version to be published.

Authorship Contributions. AGW, TAD and GGH designed the study AGW worked on the analysis, interpretation of the data, and prepared the draft manuscript. AGW, TAD and GGH prepared the final manuscript for publication. All authors read and approved the final paper.

Disclosures. Araya Gebereyesus Wasihun, Tsehaye Asmelash Dejene and Genet Gebrehiwet Hailu declare that they have no competing interests.

Compliance with Ethics Guidelines. Ethical clearance was secured from Institutional Review Board (IRB) of Aksum University; College of Health Sciences. Moreover, a letter of 
cooperation was written to each study hospital and permission to collect the data was obtained from the Amhara Public Health Institute, Dessie branch (Ref: 4/49/2019).

Data Availability. The datasets used and analyzed during the current study are available from the corresponding author on reasonable request.

Open Access. This article is licensed under a Creative Commons Attribution-NonCommercial 4.0 International License, which permits any non-commercial use, sharing, adaptation, distribution and reproduction in any medium or format, as long as you give appropriate credit to the original author(s) and the source, provide a link to the Creative Commons licence, and indicate if changes were made. The images or other third party material in this article are included in the article's Creative Commons licence, unless indicated otherwise in a credit line to the material. If material is not included in the article's Creative Commons licence and your intended use is not permitted by statutory regulation or exceeds the permitted use, you will need to obtain permission directly from the copyright holder. To view a copy of this licence, visit http://creativecommons.org/licenses/by$\mathrm{nc} / 4.0 /$.

\section{REFERENCES}

1. WHO. Global Tuberculosis Report: 2019.

2. Abebe G, Abdissa K, Abdissa A, Apers L, Agonafir M, Bouke C, et al. Relatively low primary drug resistant tuberculosis in southwestern Ethiopia. BMC Res Notes. 2012;5:1. https://doi.org/10.1186/17560500-5-225.

3. Storla DG, Yimer S, Bjune GA. A systematic review of delay in the diagnosis and treatment of tuberculosis. BMC Public Health. 2008;9:1-9. https://doi. org/10.1186/1471-2458-8-15.

4. Mulu W, Abera B, Yimer M, Hailu T, Ayele H, Abate D. Rifampicin-resistance pattern of Mycobacterium tuberculosis and associated factors among presumptive tuberculosis patients referred to Debre Markos Referral Hospital, Ethiopia: a cross-sectional study. BMC Res Notes. 2017;10:1-8. https://doi.org/ 10.1186/s13104-016-2328-4.

5. O'Riordan P, Schwab U, Logan S, Cooke G, Wilkinson CRJ, Davidson RN, Bassett P, Wall R, Pasvol G, Flanagan KL. Rapid molecular detection of rifampicin resistance facilitates early diagnosis and treatment of multi-drug resistant tuberculosis. PLoS ONE. 2008;3:1-7.

6. WHO. Rapid implementation of the Xpert MTB/RIF diagnostic test. Geneva: 2011.

7. WHO. Xpert MTB/RIF assay for the diagnosis of TB Meeting report. 2016.

8. Implementation Guideline for Xpert MTB/RIF assay In Ethiopia: Addis Ababa. 2014.

9. World Health Organization. Global tuberculosis report 2017. Geneva, Switzerland:

10. Girum T, Muktar E, Lentiro K, Wondiye H, Shewangizaw M. Epidemiology of multidrug-resistant tuberculosis ( MDR-TB ) in Ethiopia: a systematic review and meta-analysis of the prevalence, determinants and treatment outcome. Tropical Dis Travel Med Vaccines. 2018;4:1-12.

11. Arega B, Menbere F, Getachew Y. Prevalence of rifampicin resistant Mycobacterium tuberculosis among presumptive tuberculosis patients in selected governmental hospitals in Addis. BMC Infect Dis. $2019 ; 19: 1-5$.

12. Hordofa MW, Adela TB. Prevalence of refampcin mono resistant mycobacterium tuberculosis among suspected cases attending at Yirgalem Hospital. Clin Med Res. 2015;4:75-8. https://doi.org/10. 11648/j.cmr.20150403.13.

13. Ethiopia Health Sector Financing Reform/Health Finance and Governance Project: June 2018

14. Cepheid. GeneXpert Dx System Users' manual. 2012; p. 2-13.

15. Desta K, Asrat D, Lemma E, Gebeyehu M, Feleke B. Drug susceptibility of Mycobacterium tuberculosis isolates from smear negative pulmonary tuberculosis patients. Addis Ethiop J Health Dev. 2008;22: 212-5.

16. Nicol MP, Workman L, Isaacs W, Munro J, Black F, Eley B, et al. Europe PMC Funders Group Accuracy of the Xpert MTB / RIF test for the diagnosis of pulmonary tuberculosis in children admitted to hospital in Cape Town, South Africa: a descriptive study. Lancet Infect Dis. 2014;11:819-24. https:// doi.org/10.1016/S1473-3099(11)70167-0. 
17. Geleta DA, Megerssa YC, Gudeta AN, Akalu GT. Xpert MTB/RIF assay for diagnosis of pulmonary tuberculosis in sputum specimens in remote health care facility. BMC Microbiol. 2015. https://doi.org/ 10.1186/s12866-015-0566-6.

18. Mehari K, Asmelash T, Hailekiros H, Wubayehu T, Godefay $H$, Araya $T$, et al. Prevalence and factors associated with multidrug-resistant tuberculosis (MDR-TB) among presumptive MDR-TB Patients in Tigray Region, Northern Ethiopia. Can J Infect Dis Med Microbiol. 2019;2019:1-8.

19. Mulisa G, Workneh T, Hordofa N, Suaudi M, Abebe G. International journal of infectious diseases multidrug-resistant Mycobacterium tuberculosis and associated risk factors in Oromia Region of Ethiopia. Int Soc Infect Dis. 2015;39:57-61. https://doi. org/10.1016/j.ijid.2015.08.013.

20. Adane K, Ameni G, Bekele S, Abebe M, Aseffa A. Prevalence and drug resistance profile of Mycobacterium tuberculosis isolated from pulmonary tuberculosis patients attending two public hospitals in East Gojjam zone, northwest Ethiopia. BMC Public Health. 2015;15:1-8. https://doi.org/10.1186/ s12889-015-1933-9.

21. Nigus DM, Lingerew WM, Beyene BA, Tamiru AA, Lemma MT, Yimer M. Prevalence of multi drug resistant tuberculosis among presumptive multi drug resistant tuberculosis cases in Amhara National Regional State. Ethiopia J Mycobac Dis. 2014;4:2-7. https://doi.org/10.4172/2161-1068. 1000152 .

22. Farra A, Manirakiza A, Yambiyo BM, Zandanga G, Lokoti B, Berlioz-arthaud A, et al. Surveillance of rifampicin resistance with GeneXpert MTB / RIF in the National Reference Laboratory for Tuberculosis at the Institut Pasteur in Bangui, 2015-2017. Open Forum Infect Dis. 2019;6:2015-7. https://doi.org/ 10.1093/ofid/ofz075.

23. Dagnra AY, Mlaga KD, Adjoh K, Kadanga E, Disse K, Adekambi T. Prevalence of multidrug-resistant tuberculosis cases among HIV-positive and HIVnegative patients eligible for retreatment regimen in Togo using GeneXpert MTB / RIF. New Microbes New Infect. 2015;8:24-7. https://doi.org/10.1016/j. nmni.2015.09.00.

24. Denue BA, Miyanacha WJ, Wudiri Z, Alkali MB, Goni BW, Akawu CB. Rifampicin resistance among presumptive pulmonary tuberculosis cases in Borno state, North-Eastern Nigeria. Port Harcourt Med J. 2019;12:64-9. https://doi.org/10.4103/phmj.phmj.

25. Ikuabe PO, Ebuenyi ID. assay in patients with pulmonary tuberculosis in Yenagoa, Nigeria. Pan Afr Med J. 2018;29:1-4. https://doi.org/10.11604/pamj. 2018.29.204.14579.
26. Mboowa G, Namaganda C, Ssengooba W. Rifampicin resistance mutations in the $81 \mathrm{bp}$ RRDR of rpoB gene in Mycobacterium tuberculosis clinical isolates using Xpert ${ }^{\circledR}$ MTB / RIF in Kampala, Uganda: a retrospective study. BMC Infect Dis. 2014;14:1-5.

27. Sinshaw W, Kebede A, Bitew A, Tesfaye E, Tadesse M, Mehamed Z, et al. Prevalence of tuberculosis, multidrug resistant tuberculosis and associated risk factors among smear negative presumptive pulmonary tuberculosis patients in Addis. BMC Infect Dis. 2019;19:1-15.

28. Biadglegne F, Rodloff AC, Sack U. A first insight into high prevalence of undiagnosed smear-negative pulmonary tuberculosis in northern Ethiopian prisons: implications for greater investment and quality control. PLoS ONE. 2014. https://doi.org/ 10.1371/journal.pone.0106869.

29. Hamusse SD, Teshome D, Hussen MS, Demissie M, Lindtjørn B. Primary and secondary anti-tuberculosis drug resistance in Hitossa District of Arsi Zone, Oromia Regional State. Central Ethiopia BMC Public Health. 2016. https://doi.org/10.1186/ s12889-016-3210-y.

30. Sekadde MP, Wobudeya E, Joloba ML, Ssengooba W, Kisembo H. Evaluation of the Xpert MTB / RIF test for the diagnosis of childhood pulmonary tuberculosis in Uganda: a cross-sectional diagnostic study. BMC Infect Dis. 2013;13:1. https://doi.org/ 10.1186/1471-2334-13-133.

31. Ukwamedua H, Omote V, Etaghene J, Ejike M, Celia I, Agbroko H. Heliyon Rifampicin resistance among notified pulmonary tuberculosis (PTB) cases in South-Southern Nigeria. Heliyon. 2019;5:e02096. https://doi.org/10.1016/j.heliyon.2019.e02096.

32. Tesfay K, Tesfay S, Nigus E, Gebreyesus A. More than half of presumptive multidrug-resistant cases referred to a tuberculosis referral laboratory in the Tigray region of Ethiopia are multidrug resistant. Int J Mycobacteriol. 2016;5:324-7.

33. Tilahun M, Ameni G, Desta K, Zewude A, Yamuah L, Abebe M, et al. Molecular epidemiology and drug sensitivity pattern of Mycobacterium tuberculosis strains isolated from pulmonary tuberculosis patients in and around Ambo Town, Central Ethiopia. PLoS ONE. 2018;13:1-12.

34. TemboMalangu BPNG. Prevalence and factors associated with multidrug / rifampicin resistant tuberculosis among suspected drug resistant tuberculosis patients in Botswana. BMC Infect Dis. 2019;19:1-8. 